\title{
Acoustic Recordings of Greater Silver Smelt (Argentina silus) in Norwegian Waters and West of the British Isles, 1989-94
}

\author{
Terje Monstad \\ Institute of Marine Research, Bergen, Norway \\ and \\ Arne Johannessen \\ Department of Fisheries and Marine Biology, University of Bergen, Norway
}

\begin{abstract}
During spring, in the period 1989-94, greater silver smelt (Argentina silus) was recorded along the shelf edge west of the British Isles. In some years, acoustic estimates of the concentrations were made, suggesting biomass values from 200 000-400 000 tons.

In the period 1990-92, the size of greater silver smelt biomass recorded off mid-Norway in spring was also estimated, showing slightly higher values than the ones obtained west of the British Isles. In 1989, significantly less biomass was recorded in Norwegian waters during autumn than during spring.
\end{abstract}

The geographical distributions of the recordings, as well as biological parameters, such as age, length and sex compositions, are examined. Growth relations are also discussed.

Key words: acoustics, age, biomass indices, British Isles, distribution, greater silver smelt, growth, length, Norway,

\section{Introduction}

In Norway, greater silver smelt, or greater argentine (Argentina silus), has been caught as bycatch in the mixed industrial fisheries for years. In the 1970s, the commercial interest for greater silver smelt increased and a directed fishery for human consumption developed.

The species is distributed along the Norwegian coast from Skagerrak in the south to Finnmark in the north, in the slope and shelf area, as well as in the fjords. It is mainly located at depths from $200-600 \mathrm{~m}$, but occasionally down to depths of more than $1000 \mathrm{~m}$. It is also found along the slope in the western Barents Sea north to Bear Island, in the shelf area west of Scotland and Ireland and in Icelandic and East Greenland waters (Cohen, 1984).

The main spawning in Norwegian waters takes place in spring from March to May. Minor spawning also occurs throughout summer and in autumn. During the spawning period, the greater silver smelt is congregated in deeper parts of the continental shelf and along the slope, where the concentrations are dense enough to be commercially exploited. After spawning the fish disperse again over most of the shelf, staying close to bottom at depths greater than $250 \mathrm{~m}$. It occurs mixed with various other fish species, especially blue whiting (Micromesistius poutassou) and ocean perch (Sebastes marinus), but also small redfish (S. viviparus), Norway pout (Trisopterus esmarki) and silvery pout (Gadiculus argenteus).

In the shelf edge area west of the British Isles, the greater silver smelt is mainly observed down to about $750 \mathrm{~m}$, and more scattered down to about $1000 \mathrm{~m}$. It stays close to bottom along the slope up towards $200 \mathrm{~m}$ depth. From $400-500 \mathrm{~m}$ and up it is usually mixed with blue whiting during spring (Fig. 1).

Whether the greater silver smelt is rather stationary, only undertaking a pulsing migration in the spawning season, or it makes regular migrations along the coast is still uncertain. In Norwegian waters it is still considered as one stock, as it is in the area west of the British Isles. 


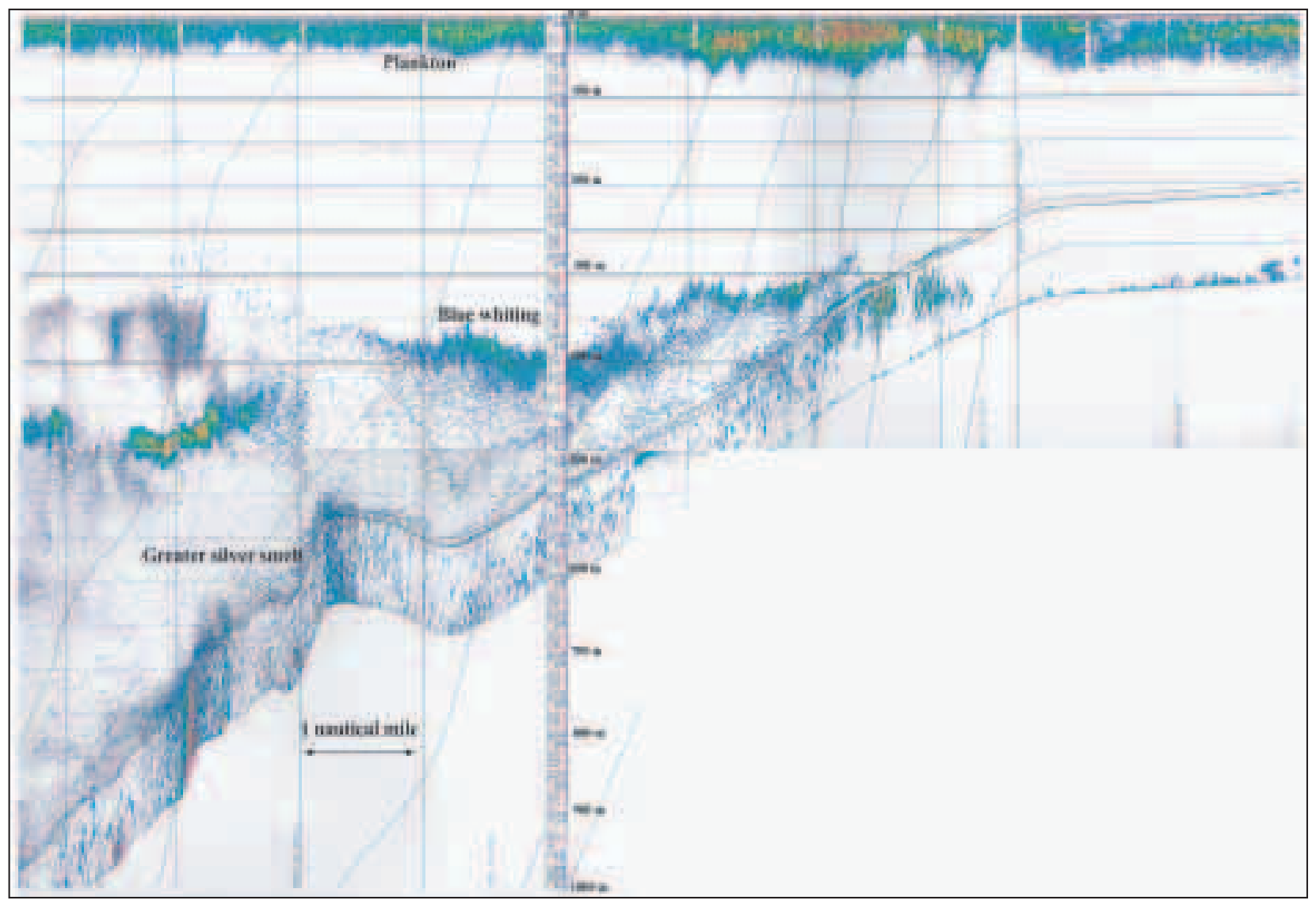

Fig. 1. Echo registrations from the continental slope Northwest of Ireland $\left(55^{\circ} 30^{\prime} \mathrm{N} 09^{\circ} 20^{\prime} \mathrm{W}\right)$ April 1999. 38kHz Simrad EK-500.

Norway started systematic investigations of greater silver smelt in 1980. During spring and autumn seasons, acoustic surveys were conducted off mid-Norway until 1992. The main purpose was to explore the state of the stock in the shelf edge area north of $62^{\circ} \mathrm{N}$, in order to consider possible recommendations for regulation of the fishery. Recordings of greater silver smelt were also obtained as observations in spring during the routine surveys on blue whiting to the west of the British Isles.

\section{Material and Methods}

\section{Survey design}

Acoustic surveys on greater silver smelt were conducted with the research vessels "G.O. Sars", "Johan Hjort" and "Michael Sars" in continental shelf edge areas, i.e. shelf, edge and slope areas. In Norwegian waters these surveys took place during autumn in 1989 (Fig. 2) and during spring in 199092. In British waters greater silver smelt was recorded during spring 1989-94, when monitoring of the blue whiting stock took place. Figures 3 and 4 gives the cruise tracks of 1990 as examples for the spring surveys in Norwegian and British waters, respectively.

\section{Equipment and calibration}

On all three vessels the echo sounder, $38 \mathrm{kHz}$ Simrad EK 500 with splitbeam transducer ES 38B, connected to BEI integrator system, was run continuously through the entire survey, and fishing with pelagic and bottom trawls were done frequently for identification and collection of biological samples. For hydrographic observations, a number of CTDstations were worked from sea surface down to $500 \mathrm{~m}$ or bottom.

The echo sounders were calibrated according to standard procedure, i.e. against a standard target 60 mm copper-sphere (Foote et al., MS 1981), prior to the surveys. The variations of the tranceivers settings between vessels and surveys were less than $0.5 \mathrm{~dB}$ (Ona, pers. comm.). 


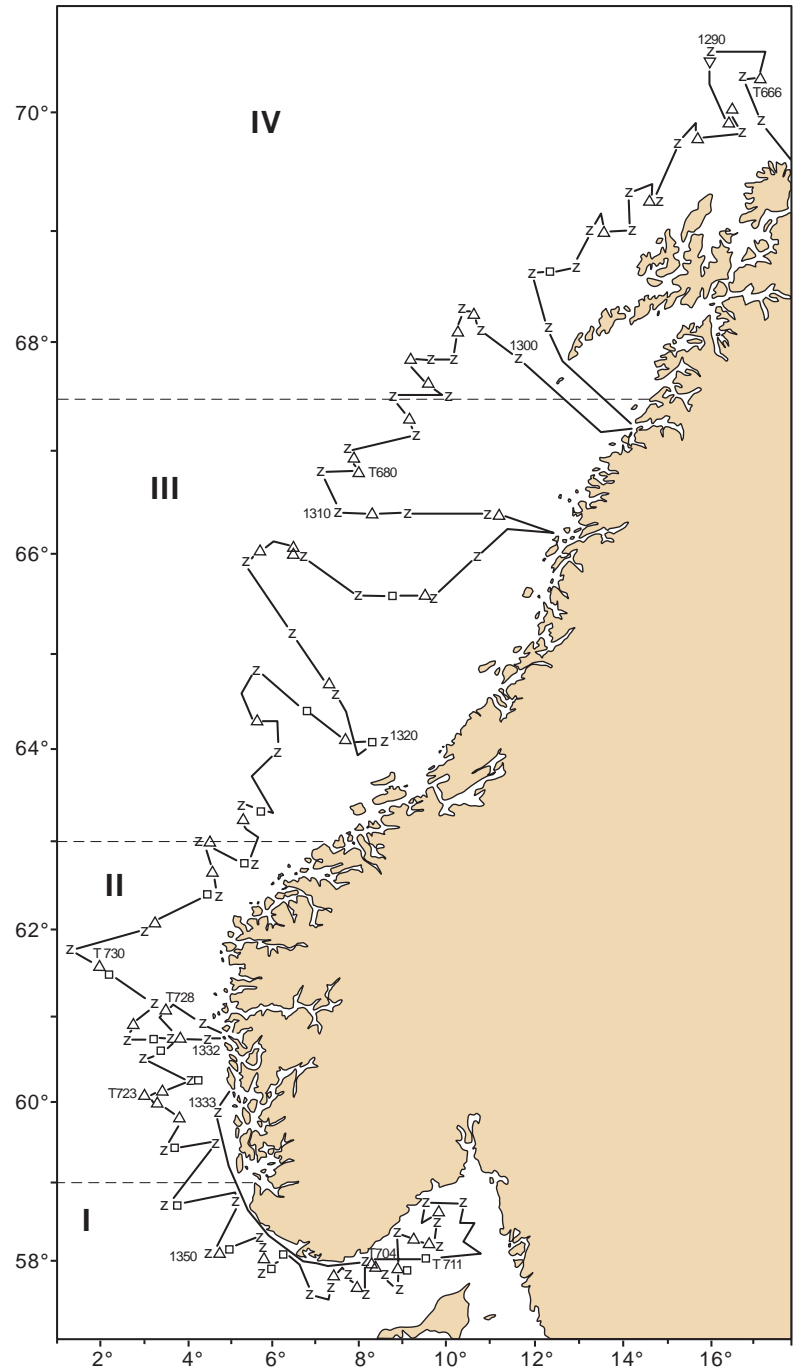

Fig. 2. Cruise tracks and stations November 1989, with subareas I-IV.

The echo intensity, i.e. the integrator output $\left(S_{A}-\right.$ value) was scrutinized for each 5 nautical mile, and together with the results of the trawl catches, the mean values were judged and divided into various fish species or groups. The method used for the calculations is described in e.g. Anon. (MS 1982 and MS 1985) and Monstad (MS 1986). The total area surveyed was divided into rectangles of $0.5^{\circ}$ latitude and $1^{\circ}$ longitude in which the average integrator value $\left(S_{A}\right)$ was calculated and area size of the distribution area measured. Representative distributions of length and weight were established for each rectangle, based on allocated trawl samples, and the "echo abundance" calculated. These were first added up for a number of sub-areas and finally pooled for the total echo abundance for the whole survey area.

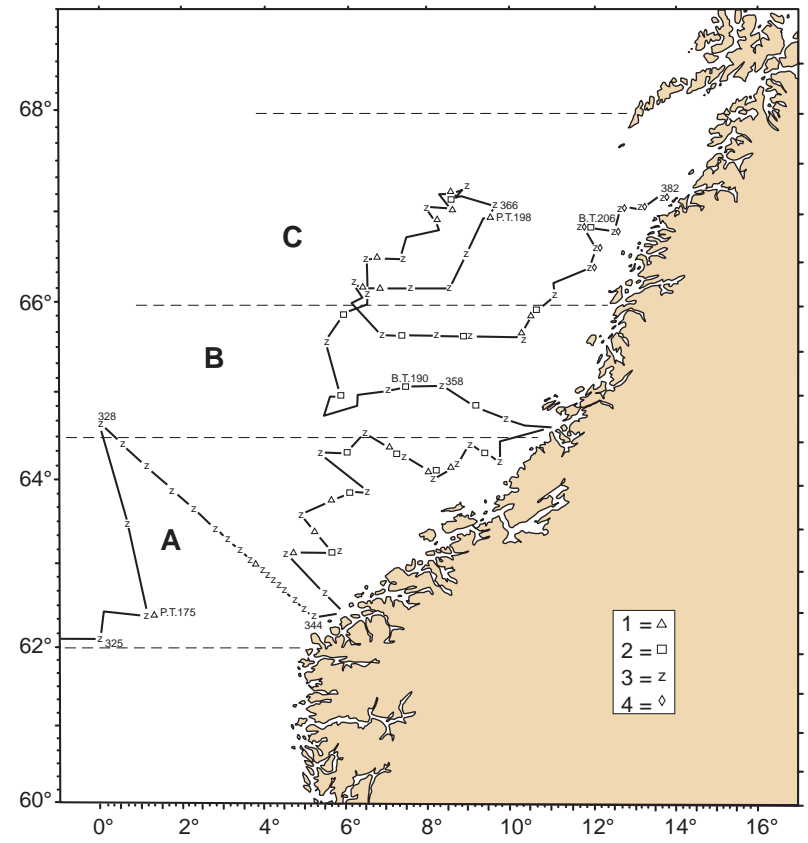

Fig. 3. Cruise tracks and stations April/May 1990, with subareas $\mathrm{A}-\mathrm{C}$.

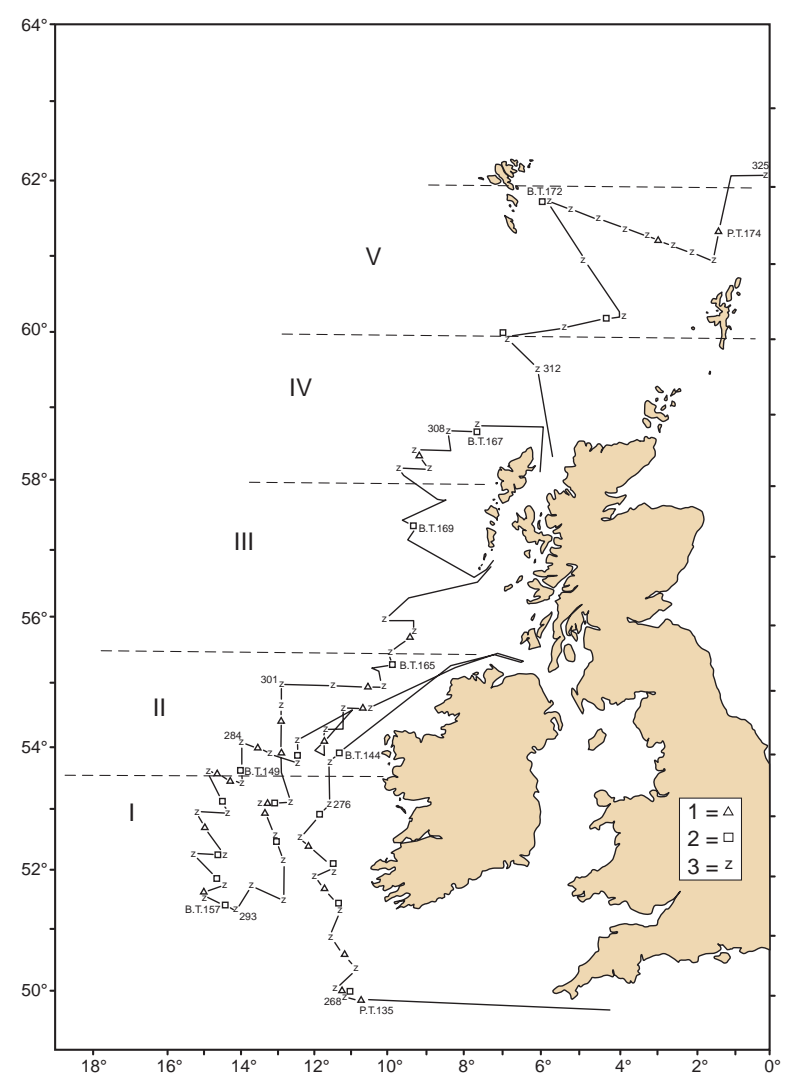

Fig. 4. Cruise tracks and stations March/April 1990, with sub-areas I-V. 


\section{Target strength}

The fundamental background for the integration method is given in Forbes and Nakken (1972), and discussions of the acoustic methods can be found in several textbooks, e.g. MacLennan and Simmonds (1992). A description of fish as an acoustic target has been given by Midttun (1984), and the problem of determining the relation between integrated echo intensity and fish density has further been described by Nakken (MS 1975). The subject is also discussed in e.g. Midttun and Nakken (1971), Foote (MS 1985a) and Ona (MS 1984 and 1990).

The acoustic cross section of a fish is length dependent. The logarithmic form of it is the target strength:

$$
T S=\log \sigma / 4 \pi
$$

where $\sigma$ is the cross section of the fish, and the relationship between the echo intensity, $S_{A}$, (output from echo integrators) and $\rho_{A}$, (number of fish per unit area) is:

$$
S_{A}=\bar{\sigma} \rho_{A}
$$

The relationship between target strength and fish length is empirically established for each species. Estimates of target strength, which are to be expected at sea are obtained by combining the experimental results with field observations of fish inclination (Nakken and Olsen, 1977).

Greater silver smelt and cod, both with swimbladder (physoclist and physostome respectively), have similar behaviour, i.e. a distribution near bottom. This may result in some greater silver smelt not being recorded by the echo sounder due to the shadow zone (e.g. Aglen et al., 1999). As a starting point the $T S$-length relation of $T S=21.8 \log L-74.9$ (Godø et al., MS 1987) applied during acoustic surveys of cod in the Barents Sea, was used to estimate the biomass of the greater silver smelt. However, the target strength value used for cod has been adjusted and improved several times, and a $T S$-length relation of $T S=21.8 \log L-72.7$ has also been applied for young cod (Anon., MS 1982).

Foote (MS 1985b) measured the target strength of greater silver smelt in situ and obtained a value of $-36.5 \mathrm{~dB}$ for a an average fish of $37.2 \mathrm{~cm}$. This value fits the TS/length relation of TS $=20 \log L-67.5$ (Foote 1987), which at present is used during the acoustic surveys for cod.
If the mean echo intensity $\left(S_{A}\right)$ within an unit area $(A)$ is known, as well as the target strength value of the fish, the number of fish then can be found:

$$
N=\rho_{a} \times A=S_{A} / \bar{\sigma} \times A
$$

Knowing the mean weight $(\bar{w})$ of these fishes the biomass, $B$, will be:

$$
B=N \times \bar{w}
$$

\section{Results and Discussion}

\section{Distribution}

\section{Norwegian Coast}

In Norwegian waters greater silver smelt is distributed along the whole coast in connection with the shelf edge area and in Skagerrak. In Fig. 5 the distributions during autumn 1989 and spring 199092 are shown, together with the temperatures at 400 $\mathrm{m}$ depth or bottom. Most of the recordings were made within the temperature range of $5^{\circ}$ to $8^{\circ} \mathrm{C}$ (Monstad MS 1990a,b, MS 1991a, and MS 1992a).

1989. No spring survey for greater silver smelt was conducted in Norwegian waters in 1989, but in autumn a rather extensive survey took place from 2 to 25 November. The shelf edge area was crisscrossed from north to south, including the Norwegian trench to Skagerrak. Greater silver smelt was recorded near bottom in a mixture with other fish species, especially redfish. Highest density was found in the south, i.e. in the Skagerrak Area.

1990. In spring 1990, greater silver smelt was recorded off the mid-Norwegian coast during 20 April-3 May. Highest concentrations were observed on the slope at position $67^{\circ} 15^{\prime} \mathrm{N} 08^{\circ} 30^{\prime} \mathrm{E}$, an area where frequent bottom-near pelagic trawling for greater silver smelt used to take place, especially for 2-3 weeks in late-April and early-May.

1991. During the period 18-28 April 1991, the acoustic survey on greater silver smelt was carried out in the shelf area off mid-Norway. As in previous years, the best concentrations were recorded along the continental slope, but more to the south than usual, i.e. a shift from $67^{\circ} \mathrm{N}$ to $65^{\circ} \mathrm{N}$. Greater silver smelt was also in some part of the area found nearer land than usual.

1992. The acoustic survey for greater silver smelt in 1992 was conducted from 21 April-4 May. It 

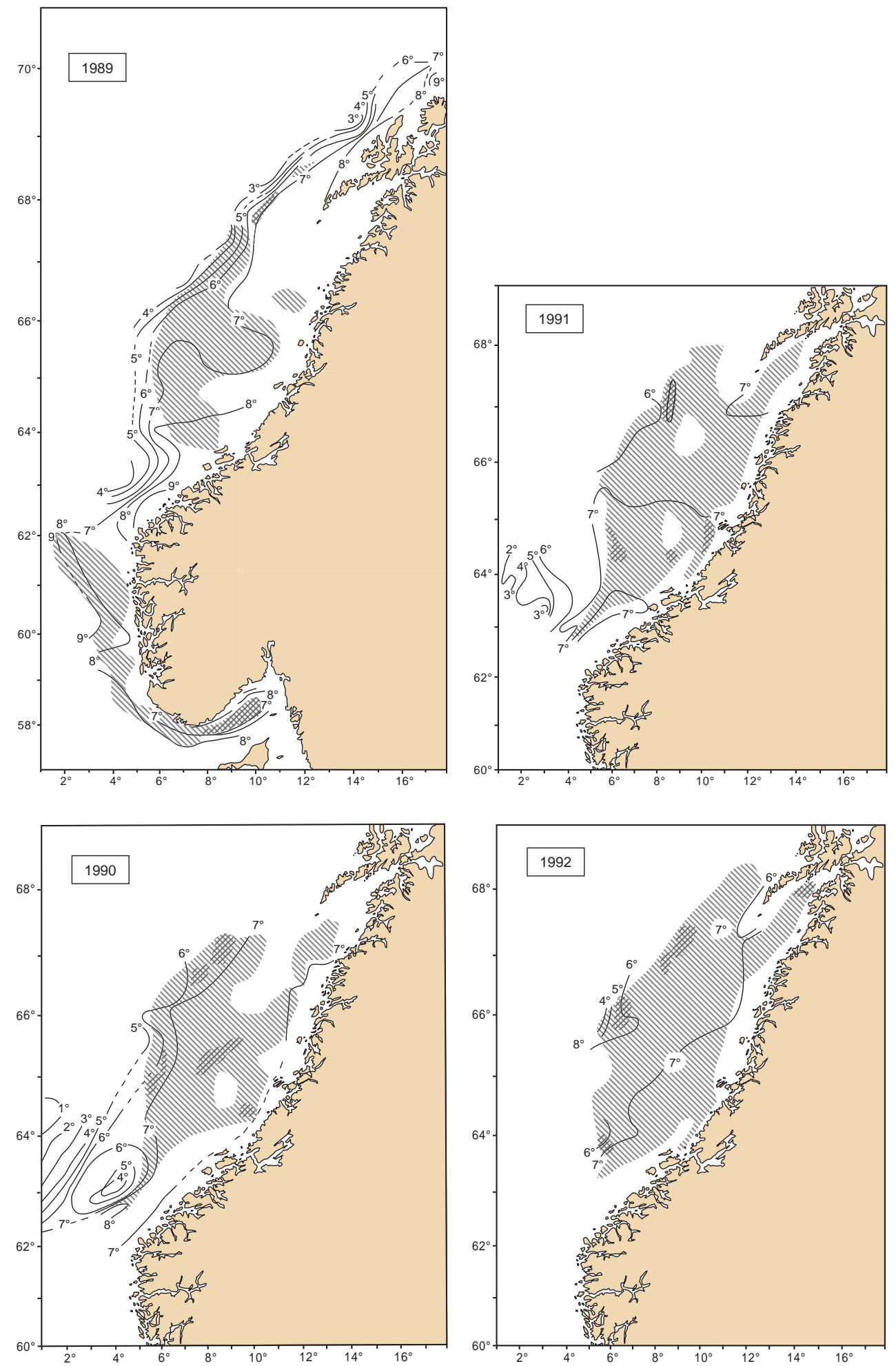

Fig. 5. Distribution of greater silver smelt in autumn 1989 and in spring 1990-92. Temperature, $t^{\circ} \mathrm{C}$, at bottom or $500 \mathrm{~m}$ in 1989 and at bottom or $400 \mathrm{~m}$ in 1990-92. 
covered the area between $63^{\circ} \mathrm{N}-68^{\circ} \mathrm{N}$ including the Vestfjorden, i.e. inside the Lofoten Isles. The highest concentrations were also this year found along the shelf edge, and again in the traditional areas at $67^{\circ} \mathrm{N}$ and $66^{\circ} \mathrm{N}$, as well as in deeper parts of the Vestfjorden.

\section{West of the British Isles}

In British waters greater silver smelt is found along the shelf edge area from north of Shetland to south of Ireland. It is located near bottom mainly between 300 and $750 \mathrm{~m}$ depth, but occurs also higher up as well as down to depths of about $1000 \mathrm{~m}$. The distributions and temperature at $400 \mathrm{~m}$ or bottom observed in spring 1989-94 are shown on Fig. 6A and B. In the north, the species was mainly observed in water of $7^{\circ}-9^{\circ} \mathrm{C}$, whereas in the south from $9^{\circ}-11^{\circ} \mathrm{C}$ (Monstad MS 1989, MS 1990b, MS 1991b, MS 1992b, MS 1993, MS 1994).

1989. During the acoustic survey from 30 March24 April 1989 greater silver smelt was recorded at or near bottom over a rather large area. The concentrations, both at the Porcupine Bank off Ireland and from the Hebrides to Shetland, were recorded at bottom mainly between 300 and $600 \mathrm{~m}$. In the most shallow areas of the Porcupine Bank, less than $300 \mathrm{~m}$, some faint concentrations of lesser silver smelt (A. sphyraena) were also observed.

1990. From 29 March to 20 April 1990, greater silver smelt was recorded more or less along the whole shelf edge area from south of the Porcupine Bank to north of Shetland. The highest densities of the concentrations were observed in the southwestern part of the Porcupine Bank and off the Hebrides, while elsewhere they were mostly moderate and scattered. At the eastern part of the Porcupine Bank and in the slope area south of Ireland, some lesser silver smelt was also observed at depths less than $300 \mathrm{~m}$.

1991. As in the previous year, greater silver smelt was recorded along most of the shelf edge area from southwest of Ireland to the Faroe/Shetland area. The occurrences were mostly scattered near bottom, with notable densities only within some minor areas.

1992. The distribution and echo densities of greater silver smelt, recorded from 10 March to 6 April 1992, were very similar to the distributions observed in 1990 and 1991. Most of the recordings were scattered, and only a few minor areas of notable densities were observed.
1993. During the acoustic survey from 8 March to 4 April 1993, scattered recordings of greater silver smelt were made from the slope area south of Ireland to west of Shetland. Only within limited areas at the western and the southern part of the Porcupine Bank were some higher density concentrations observed. While the distribution of greater silver smelt was very similar to that of previous years, the recordings were considerably weaker than usual.

1994. Mostly faint recordings of greater silver smelt were made throughout the survey period of 25 March-15 April 1994. The distribution was very much like that of previous years, located near bottom together with blue whiting and other demersal species.

\section{Acoustic estimates}

Several attempts were in the early 1980 's made to estimate the abundance and biomass of greater silver smelt acoustically, but due to the mingling with other species and the near bottom distribution, it was difficult to obtain proper allocation to greater silver smelt from the recorded total integrator intensity (e.g. Johansen and Monstad, MS 1982). Too many potential errors were introduced to give reliable estimates. However, when the $38 \mathrm{kHz}$ echo sounder EK-500 was introduced in 1989, together with the new integrator system BEI (Bergen Echo Integrator), the tool for recordings of fish data and the handling of it became considerably improved. Hence the first acoustic estimate of greater silver smelt in Norwegian waters was presented from the extensive survey in November 1989 (Monstad, MS 1990a).

Subsequently, acoustic estimates of greater silver smelt were possible when the survey conditions gave sufficient basis for such calculations. A number of errors have implications for the survey estimates given, of which the near bottom distribution at large depths and the mixture with other species are considered the major ones. Although there have been improvement in the methodology, these sources of error still make the estimates uncertain. An additional source of error in the estimation of absolute biomass of greater silver smelt is the target strength.

The cod-value of $T S_{1}=21.8 \log L-74.9$ was first applied in the calculation of absolute biomass of greater silver smelt. However, in Table 1 the results of absolute biomass estimates are given using the three target strength-length relations described in the materials and methods section. The table demonstrates 

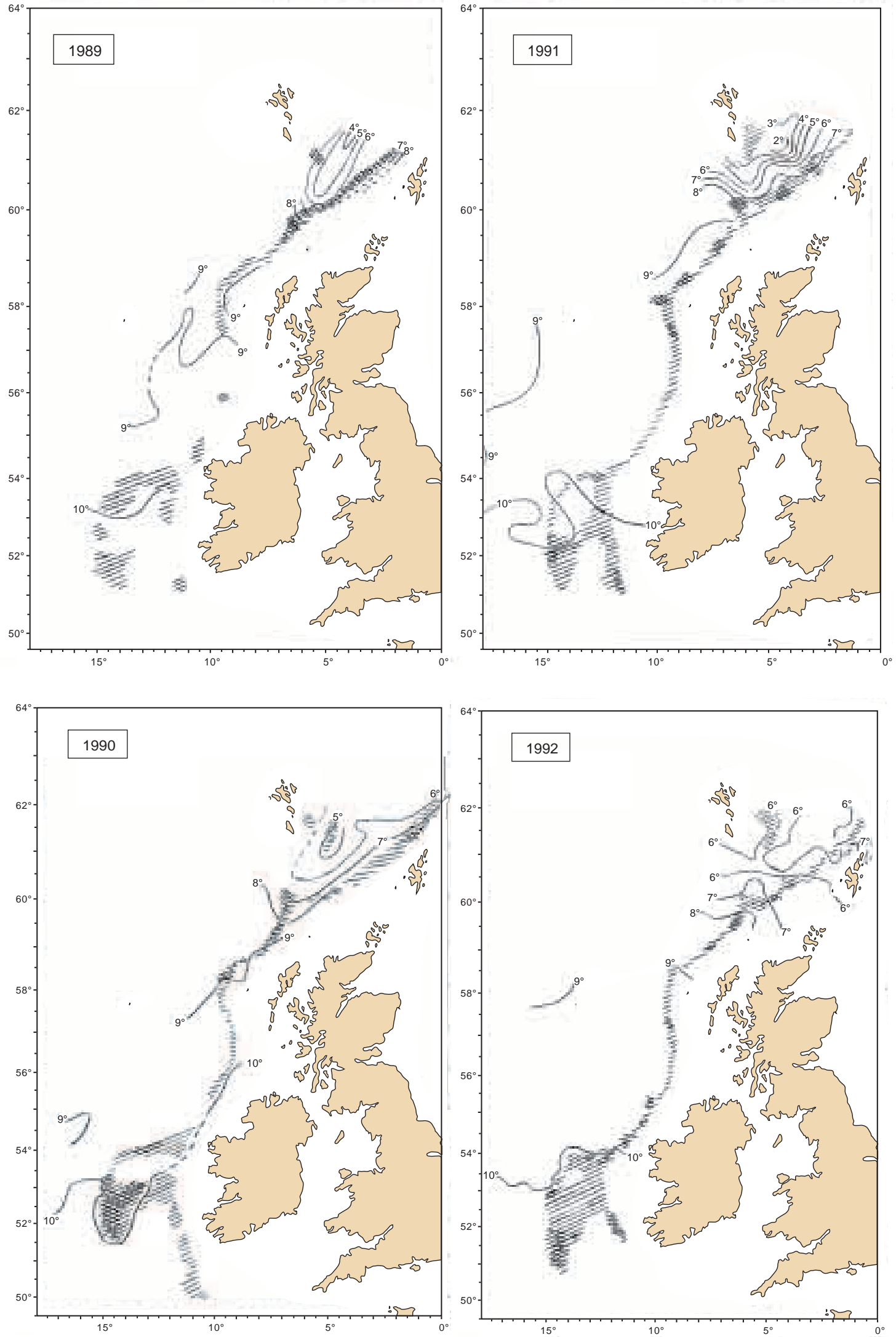

Fig. 6A. Distribution of greater silver smelt in spring 1989-92 with $t^{\circ} \mathrm{C}$ at bottom or $400 \mathrm{~m}$. 


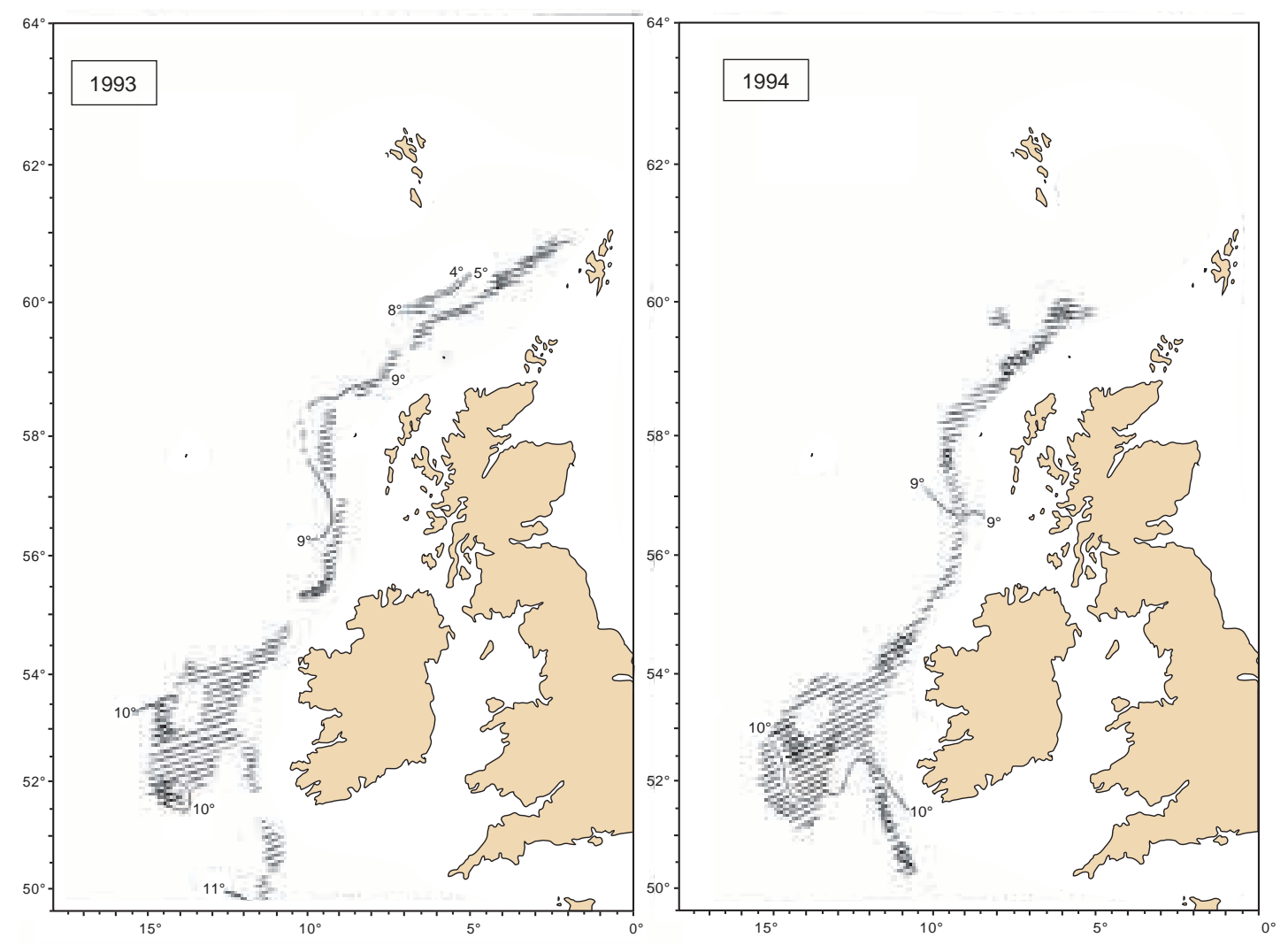

Fig. 6B. Distribution of greater silver smelt in spring 1993-94 with $t^{\circ} \mathrm{C}$ at bottom or $400 \mathrm{~m}$.

the uncertainty due to lack of knowledge of the target strength-length relation, and the numbers should consequently be regarded as indices only.

In 1989 the stock along the whole coast from North-Norway to Skagerrak was surveyed during autumn (Fig. 2 and 5). The total results are thus presented in the table, and for comparison with the other years, also the results from the area north of $62^{\circ} \mathrm{N}$. The abundance and biomass indices obtained for that area are approximately half the corresponding indices for the total area (Table 1).

Disregarding the results of autumn 1989 in Norwegian waters and that of spring 1993 in British waters, the obtained indices show similar levels of greater silver smelt in the two regions. The first target strength value applied $\left(T S_{1}\right)$ suggests stock size levels from at $395000-450000$ tons, while the value earlier used for young cod $\left(T S_{2}\right)$ suggests a level of around 250000 tons. However, if the presently used target strength value for cod $\left(T S_{3}\right)$ is to be considered the most reliable one also for greater silver smelt, the stock size in Norwegian waters, as well as in British waters, should be reduced to levels of less than 200000 tons.

It has been suggested for some species (cod and herring) that other factors, such as gonad development, tilt angle and behaviour, can affect the target strength values to change by $2 \mathrm{~dB}$ (Ona 1990), and this would affect the biomass estimates significantly.

Taking into account all the uncertainties implied, and assuming that the total area of distribution has not been fully surveyed, the size of the stock in Norwegian waters could be in the order of 200000 400000 tons. As mentioned above, this could also be the level for the stock size in the shelf edge area to the west of the British Isles.

To get reliable stock estimates of greater silver smelt, more research is needed on its acoustic relations, i.e. target strength measurements and the establishment of a density coefficient, as well as more investigations of the fish community in its habitat, in order to better determine each species' contribution to the total echo intensity. 
TABLE 1. Acoustic estimates of greater silver smelt, based on 3 different target strength values: $T S_{1}=21.8 \log \mathrm{L}_{-} 74.9, T S_{2}$ $=21.8 \log L-72.7, T S_{3}=20.0 \log L-67.4$. Biomass in 1000 metric tons (mt).

\begin{tabular}{|c|c|c|c|c|c|c|c|c|c|c|c|c|}
\hline & \multicolumn{6}{|c|}{ West of British Isles } & \multicolumn{6}{|c|}{ Norwegian Coast } \\
\hline & \multicolumn{2}{|c|}{$T S_{1}$} & \multicolumn{2}{|c|}{$T S_{2}$} & \multicolumn{2}{|c|}{$T S_{3}$} & \multicolumn{2}{|c|}{$T S_{1}$} & \multicolumn{2}{|c|}{$T S_{2}$} & \multicolumn{2}{|c|}{$T S_{3}$} \\
\hline & biomass & $\mathrm{N} \times 10^{-9}$ & biomass & $\mathrm{N} \times 10^{-9}$ & biomass & $\mathrm{N} \times 10^{-9}$ & biomass & $\mathrm{N} \times 10^{-9}$ & biomass & $\mathrm{N} \times 10^{-9}$ & biomass & $\mathrm{N} \times 10^{-9}$ \\
\hline $1989^{1}$ & - & - & - & - & - & - & 324 & 1.0 & 194 & 0.6 & 130 & 0.4 \\
\hline $1989^{2}$ & - & - & - & - & - & - & 168 & 0.5 & 101 & 0.3 & 67 & 0.2 \\
\hline 1990 & 395 & 2.1 & 237 & 1.3 & 158 & 0.8 & 419 & 1.7 & 251 & 1.0 & 168 & 0.7 \\
\hline 1991 & 400 & 2.0 & 240 & 1.2 & 160 & 0.8 & 450 & 1.3 & 270 & 0.8 & 180 & 0.5 \\
\hline 1992 & - & - & - & - & - & - & 402 & 1.4 & 241 & 0.8 & 161 & 0.6 \\
\hline 1993 & 208 & 2.0 & 124 & 1.2 & 83 & 0.8 & - & - & - & - & - & - \\
\hline
\end{tabular}

1 Total

2 Area north of $62^{\circ} \mathrm{N}$

- No estimate.

\section{Age and length}

Samples of greater silver smelt from Norwegian waters were generally dominated by fish of 15 years of age and older. The length ranged from about 15 to $48 \mathrm{~cm}$, with peaks between 35 and $40 \mathrm{~cm}$.

In British waters the lengths generally spanned over the same range as in Norwegian waters, but most of the fish observed belonged to the age groups 2-6 years. The $15+$ age group was mostly found in the north, i.e. north of the Hebrides and the Faroe/ Shetland area.

The situation during autumn in Norwegian waters is represented by the extended survey in November 1989, of which Fig. 7 shows the length and age compositions for the 4 Subareas marked on Fig. 2. In the north, i.e. north of $67^{\circ} 30^{\prime} \mathrm{N}$ (sub-area IV in Fig. 2 ), where only small numbers were sampled, the length ranged from 20 to $45 \mathrm{~cm}$. Young fish, 2 and 3 years old, contributed most in this area. The largest and oldest specimens occurred off mid-Norway, $63^{\circ} 00^{\prime}-67^{\circ} 30^{\prime} \mathrm{N}$ and in the Norwegian Trench, i.e. south of $59^{\circ} \mathrm{N}$ (sub-areas I and III in Fig. 2). In these areas, more than $50 \%$ of fish 20 years and older contributed to the stock, with lengths ranging from 13 to $46 \mathrm{~cm}$.

The situation during spring may be represented by the surveys in 1990 and 1992. Off the Norwegian coast in 1990 (Fig. 8) the largest and oldest fish were found in the north (sub-area $\mathrm{C}$ in Fig. 3), where more than $60 \%$ were 15 years and older. Younger fish occurred more to the south (sub-area $A$ and $B$ in
Fig. 3). The 3- and 4-year-old fish contributed at the same level as the age group $15+$, i.e. with $20-25 \%$.

In British waters the largest fish in 1990 were also found in the north, off the Hebrides and Shetland. The 15 years and older fish contributed $30 \%$ to the stock in the area, while in the southern area the much younger fish dominated (Fig. 9), the 4-year-old contributing more than $50 \%$.

The great depths of occurrence and the large span of distribution make the sampling of greater silver smelt rather difficult. The conditions for trawling were sometimes so bad that the obtained biological samples could not be considered sufficiently representative for the concentrations in the localities. In Norwegian waters, the length and age were found to increase with increasing depth (Johannessen and Monstad, MS 1984). For British water, this was not the case, but decreasing mean lengths were observed south- and westwards (Johansen and Monstad, MS 1982).

In British waters, the age composition in spring 1991 differed clearly from that obtained in spring 1993, when much younger fish dominated. In 1991, the 5- and 6-year-old fish jointly made up $45 \%$ of the samples, while in 1993 the 2-year-olds contributed this value alone (Fig. 10). This explains the equal numbers acoustically estimated in the two years, although the biomass was the double in 1991 (Table 1).

The depths of trawl catches containing greater silver smelt in 1991 ranged from 180-520 m, with an un-weighted mean of $363 \mathrm{~m}$, while in 1993 it was from 280-620 m with a mean of $427 \mathrm{~m}$. 

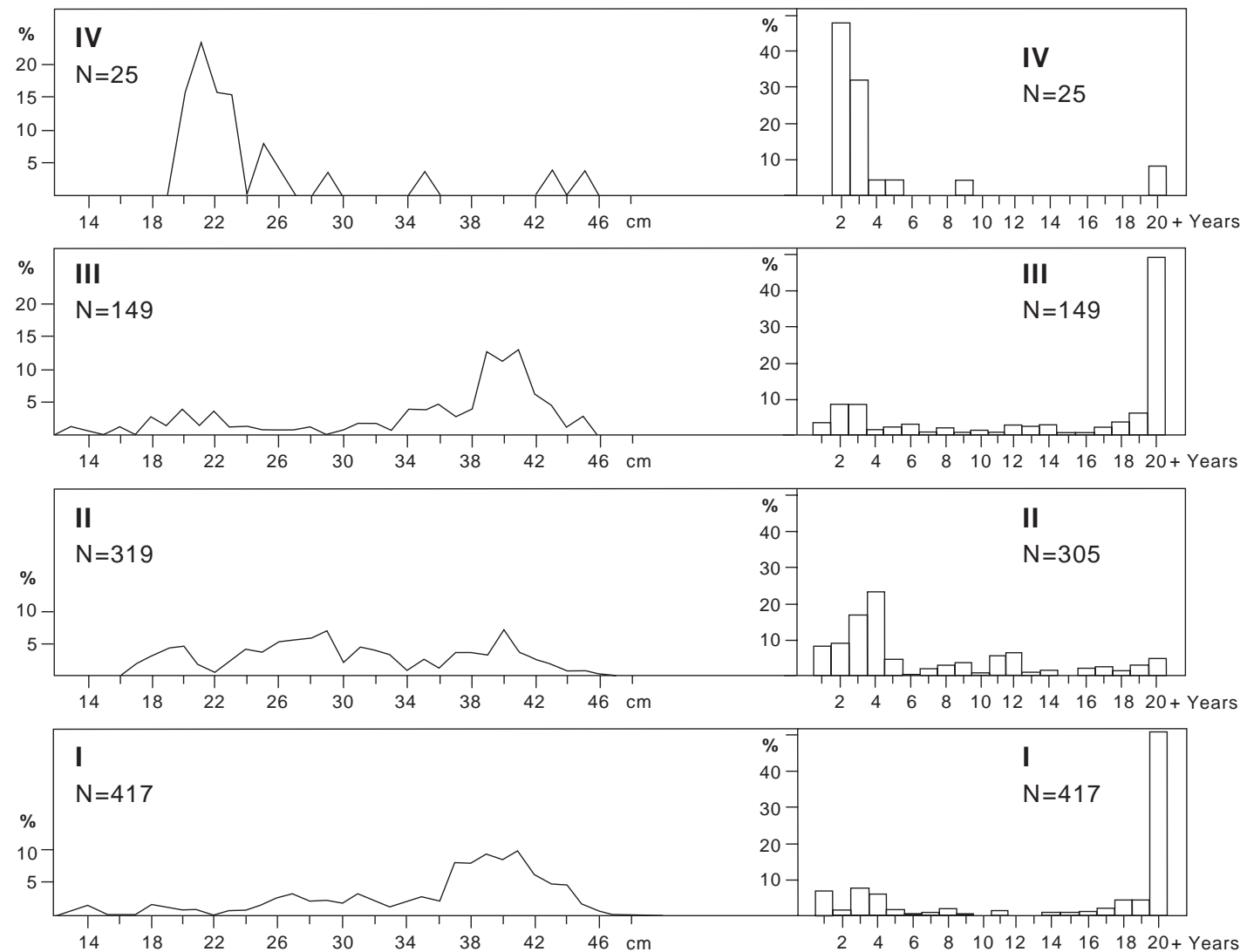

Fig. 7. Length and age distributions of greater silver smelt in samples from the Norwegian coast, autumn 1989. subareas I-IV marked on Fig. 2.
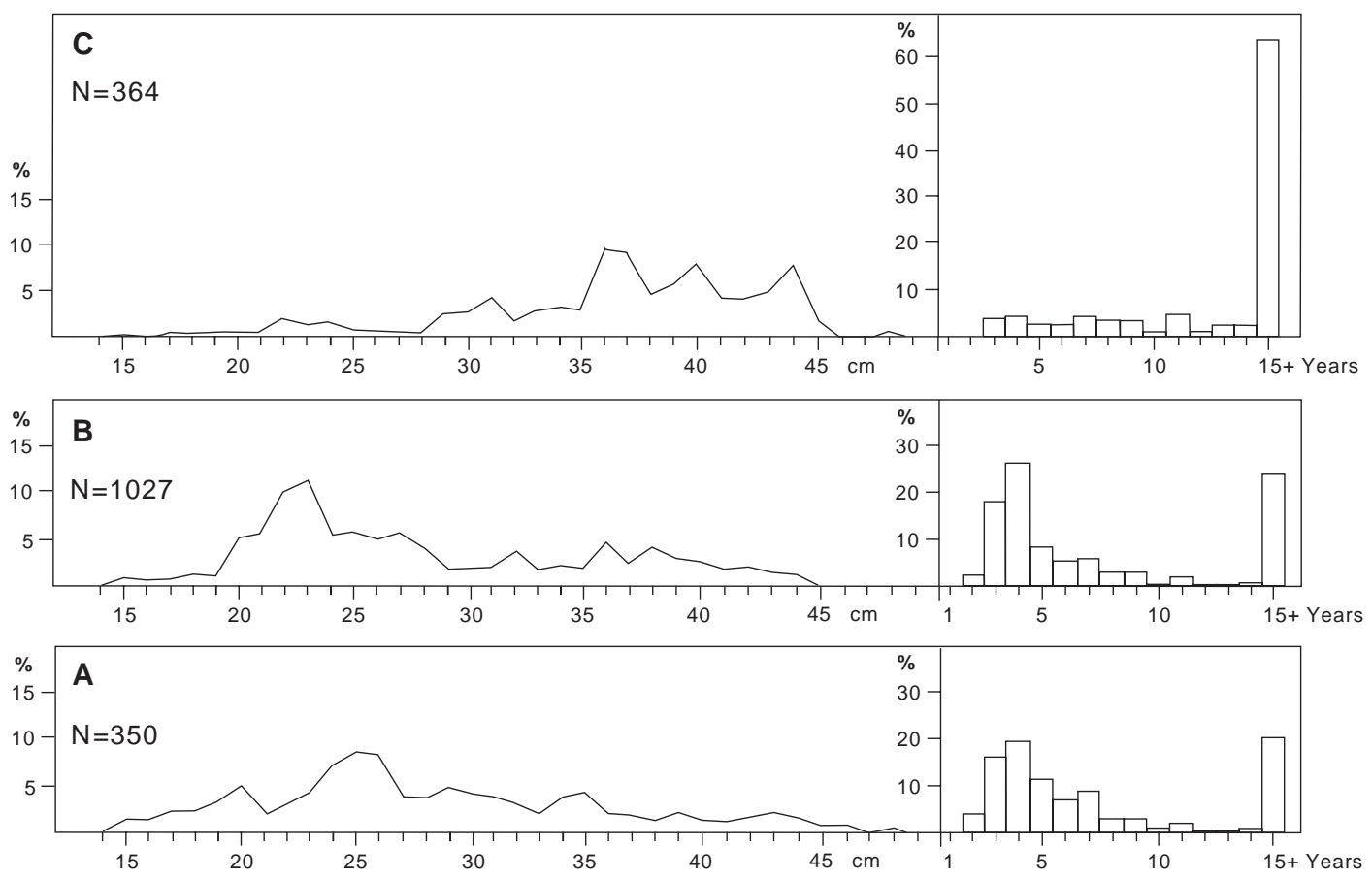

Fig. 8. Length and age distributions of greater silver smelt from the Norwegian coast, spring 1990. Sub-areas A-B marked on Fig. 3. 

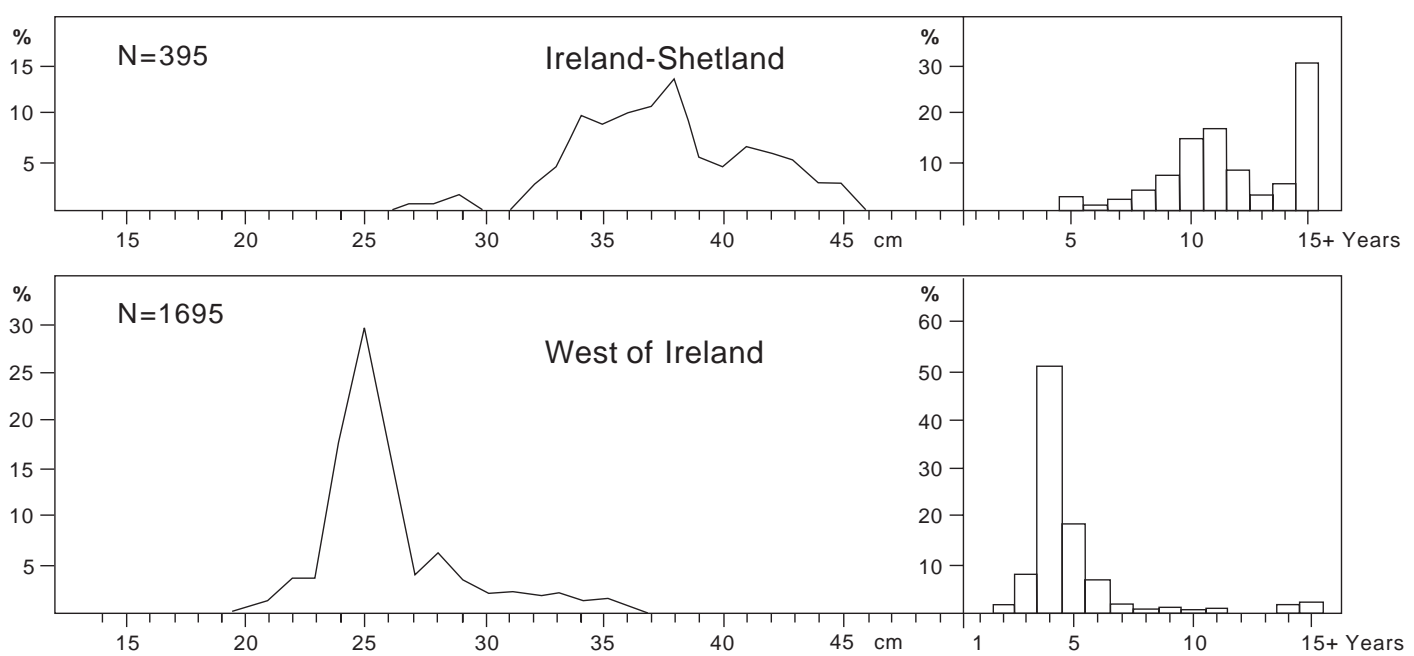

Fig. 9. Length and age distributions of greater silver smelt from west of the British Isles, spring 1990.

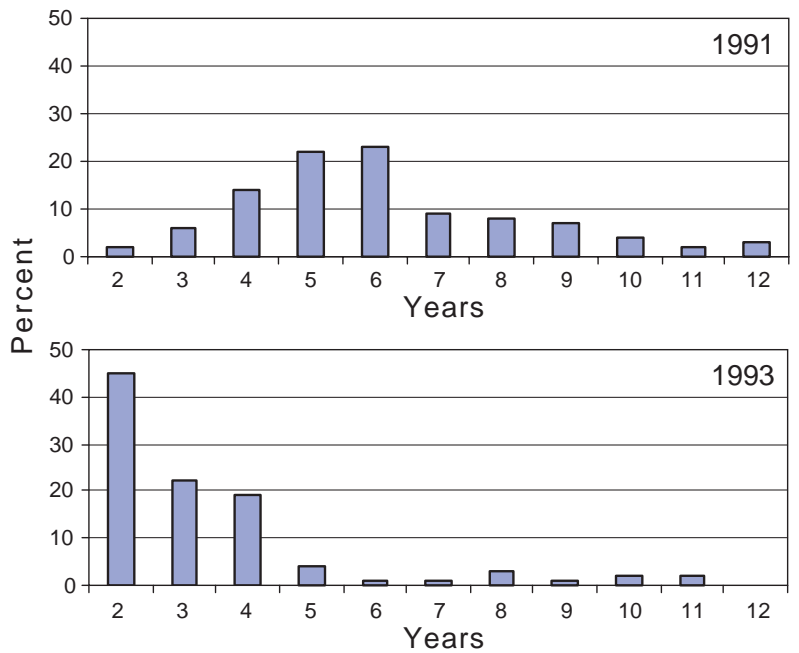

Fig. 10. Age compositions ( $\mathrm{N} \%$ ) of greater silver smelt in the area west of the British Isles in spring 1991 and 1993. Equal numbers weighted by abundance.

\section{Growth}

The length growth of greater silver smelt from British and from Norwegian waters, based on samples from the spring surveys in 1990, are shown on Fig. 11, combined for both sexes. The 11 samples from British waters have jointly $46 \%$ females and $54 \%$ males, while the 15 samples from Norwegian waters have $40 \%$ females and $60 \%$ males. The curves clearly illustrate higher mean length-at-age off Britain than off the Norwegian coast, except for age groups 11,13 and 14 years. It is noteworthy, however, that the growth curves are parallel.
Faster growth of greater silver smelt from the British Isles/Faroes than from the Norwegian coast was demonstrated by Johansen and Monstad (MS 1982). They also showed that females had a significantly larger length at age than males from the age of 7-8 years in Norwegian waters, and a significantly difference in length at age for the 10,11 and 14 year-olds. For Norwegian waters, they also found that the growth rate for males was slower than for females, but there were great variations both between and within various areas. In addition, increasing maximum lengths with increasing latitudes were observed.

\section{Conclusions}

In Norwegian waters, greater silver smelt was recorded along the whole continental shelf edge area and in the Norwegian Trench. In British waters, it was recorded in connection with the shelf edge, from north of Shetland to south of Ireland.

Due to the extensive vertical distributions of greater silver smelt, it is hard to obtain representative samples of the species. Uncertainties may therefore occur in the biological parameters as well as acoustic measurements.

Samples from the Norwegian coast were mostly dominated by individuals of age 15 years and older, with the largest and oldest ones observed off midNorway and in Skagerrak. In British waters, the age group $15+$ was most frequently found in the north. 


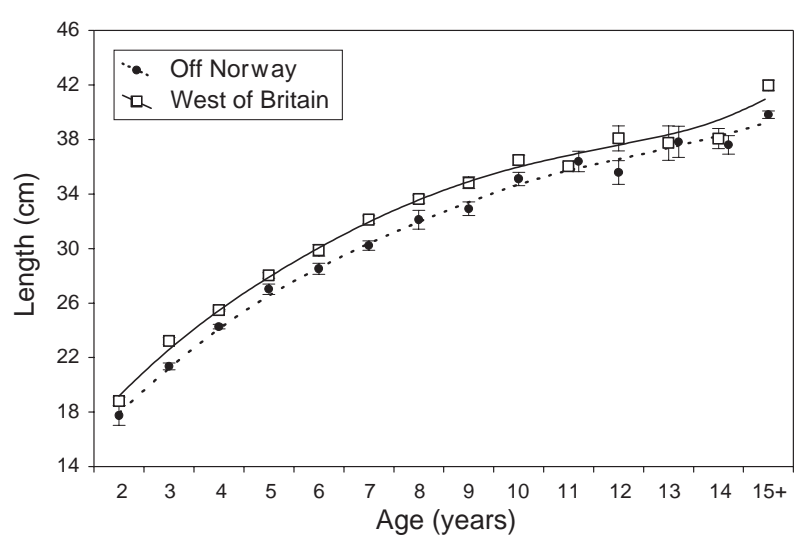

Fig. 11. Mean lengths at age with 2 standard errors, of greater silver smelt in Norwegian and British waters, spring 1990. Curves fitted by the 'least square method'.

Although no specific density coefficient is yet established for greater silver smelt and various uncertainties are implied in the allocation of the acoustic values, preliminary indices of the stock size were produced.

An overall consideration of the obtained results can indicate stock size levels of 200 000-400 000 tons in Norwegian waters as well as in British waters.

The greater silver smelt had larger mean lengthat-age west of the British Isles than off Norway, but the growth curves from the two regions were found to be rather parallel.

\section{Acknowledgement}

The authors are grateful to I. Røttingen for critical comments on the acoustic part, to Ø. Tangen and O. Gullaksen for working up the biological samples including ageing of the otoliths and to J. Alvarez for technical assistance with the figures. O. Gullaksen is also thanked for proofreading.

\section{References}

AGLEN, A., ENGÅS, A., HUSE, I., MICHALSEN, K and STENSHOLT, B.K. 1999. How vertical fish distribution may affect survey results. ICES J. Mar. Sci., 56: 345360 .

ANON. MS 1982. Report of the international acoustic survey on blue whiting in the Norwegian Sea, July/August 1982. ICES C.M. Doc., No. H:5.

MS 1985. Acoustic survey on blue whiting in the Norwegian Sea, August/September 1985. ICES C.M. Doc., No. H:4.
COHEN, D. M. 1984. Argentinidae (including Microstomatidae). In: Fishes of the North-eastern Atlantic and the Mediterranean. Whitehead, P. J. P., M-L. Bauchot, J.-C Hureau, J. Nielsen and E. Tortonese (eds.). UNESCO, Volume I: 387-388.

FOOTE, K. G., H. P. KNUDSEN, and G. VESTNES. MS 1981. Improved calibration of hydroacoustic equipment with copper spheres. ICES C.M. Doc., No. B:20.

FOOTE, K. G. MS 1985a. Effect of swimming on fish target strength. ICES C.M. Doc., No. B:29.

MS 1985b. In situ target strengths derived with a split-beam echo sounder. ICES C.M. Doc., No. B:28.

1987. Fish target strengths for use in echo integrator surveys. J. Acoust. Soc. Am., 82(3): 981-987.

FORBES, S. T. and O. NAKKEN. 1972 (Eds.). Manual of methods for fisheries resource survey and appraisal. Part 2 . The use of acoustic instruments for fish detection and abundance estimation. FAO, Rome 1972.

GODØ, O. R., A. HYLEN, J. A., JACOBSEN, T. JAKOBSEN, S. MEHL, K. NEDREAAS, and K. SUNNANÅ. MS 1987. Estimates of stock size of northeast arctic cod and haddock from survey data 1986/1987. ICES C.M. Doc., No. G:37.

JOHANNESSEN, A. and T. MONSTAD. MS 1984. Bestandsundersøkelser på vassild. [Stock investigations on greater silver smelt] Sluttrapport NFFR., Institute of Marine Research, Bergen, 30 March, 1984. 74 pp. (in Norwegian).

JOHANSEN, P. O. and T. MONSTAD. MS 1982. Preliminary results of Norwegian investigations on greater silver smelt, Argentina silus (Ascanius). ICES C.M. Doc., No. G:10.

MACLENNAN, D. N. and E. J. SIMMONDS. 1992. Fisheries Acoustics. Fish and Fisheries Series 5. Chapman and Hall, London. 325 pp.

MIDTTUN, L. 1984. Fish and other organisms as acoustic targets. ICES Rapp. Proc.-Verb., 184: 25-33.

MIDTTUN, L. and O. NAKKEN. 1971. On acoustic identification, sizing and abundance estimation of fish. FiskDir. Skr. Ser. HavUnders., 16: 36-48.

MONSTAD, T. MS 1986. Report of the Norwegian surveys on blue whiting during spring 1986. ICES C.M. Doc., No. 1986/H: 53.

MS 1989. Cruise report from R.V. "G. O. Sars", 30 March-24 April 1989: [Acoustic investigations of the blue whiting spawning stock in the area west of the British Isles]. Institute of Marine Research, Bergen, July 1991. (In Norwegian).

MS 1990a. Cruise report from R.V. "G. O. Sars", 2-25 Nov. 1989: [Investigations on blue whiting and greater silver smelt in the shelf edge area and coastal banks from Troms to Stad and in the Norwegian trench]. Institute of Marine Research, Bergen, March 1990. (in Norwegian).

MS 1990b. Cruise report from R.V. "G. O. Sars", 22 March-3 May 1990: [Investigations on blue whiting and greater silver smelt west of the British Isles and at the Norwegian coast from Stad to Vestfjorden]. Institute of Marine Research, Bergen, July 1990. (in Norwegian). 
MS 1991a. Cruise report from R.V. "Johan Hjort", 18-28 April 1991: [Investigations on blue whiting and greater silver smelt along the Norwegian coast from Stad to Vestfjorden]. Institute of Marine Research, Bergen, August 1991. (in Norwegian).

MS 1991b. Cruise report from R.V. "Johan Hjort", 15 March-17 April 1991: [Investigations on blue whiting in the shelf edge area west of the British Isles]. Institute of Marine Research, Bergen, July 1991. (in Norwegian).

MS 1992a. Cruise report from R.V. "Michael Sars", 21 April-4 May 1992: [Acoustic investigations of greater silver smelt and blue whiting in the coastal and shelf edge area from Lofoten to Stad]. Institute of Marine Research, Bergen, July 1991. (in Norwegian).

MS 1992b. Cruise report from R.V. "Johan Hjort", 1 March-6 April 1992: [Acoustic investigations of the blue whiting spawning stock in the shelf edge and bank area west of the British Isles]. Institute of Marine Research, Bergen, July 1991. (in Norwegian).

MS 1993. Cruise report from: R.V. "G. O. Sars",
8 March-4 April 1993: [Acoustic investigations of the blue whiting spawning stock in the shelf edge and bank area west of the British Isles]. Institute of Marine Research, Bergen, July 1991. (in Norwegian).

MS 1994. Cruise report from R.V. "Johan Hjort", 21 March-26 April 1994: [Acoustic investigations of the blue whiting spawning stock along the continental slope west of the British Isles from south of Ireland to north of Scotland]. Institute of Marine Research, Bergen, July 1991. (in Norwegian).

NAKKEN. O. MS 1975. On the problem of determining the relationship between integrated echo intensity and fish density. ICES C.M. Doc., No. B:26.

NAKKEN. O and K. OLSEN. 1977. Target strength measurements of fish. ICES Rapp. Proc.-Verb, 170: 52-69.

ONA, E. MS 1984. Tilt angle measurements on herring. ICES C.M. Doc., No. B:19.

ONA, E. 1990. Physiological factors causing natural variations in acoustic target strength of fish. J. Mar. Biol. Assoc. U.K., 70: 107-127. 
